\title{
In vitro and In vivo Antiamoebic Potential of Actinopyga lecanora (Jaeger)
}

\author{
Vijai Lakshmi $^{1}$ and Sheela Ghosal ${ }^{2}$ \\ ${ }^{1}$ Medicinal and Process Chemistry, Central Drug Research Institute, Lucknow-226001, India \\ ${ }^{2}$ Divisions of Microbiology, Central Drug Research Institute, Lucknow-226001, India
}

Received: April 20, 2015; Accepted: June 05, 2015; Published (Web): July 21, 2015

\begin{abstract}
Human amoebiasis, due to Entamoeba histolytica infection, is mainly associated with morbidity thus affecting the quality of life and pace of development in the countries with warm climatic conditions. So far, the available drugs provide only symptomatic relief and they are not devoid of side effects. This leads to obtain novel molecules from natural sources having antiamoebic activity. The methanol extract of Actinopyga lecanora (Jaeger) displayed antiamoebic activity. It showed MIC $125 \mu \mathrm{g} / \mathrm{ml}$ in our in-vitro studies, but when it was tested in rats, it revealed $88 \%$ inhibition of trophozoites at the dose of $900 \mathrm{mg} / \mathrm{kg}$ body weight against Entamoeba histolytica. Further work is in progress for the isolation and characterization of active molecules.
\end{abstract}

Key words: Anti-amoebic activity, Actinopyga lecanora (Jaeger), Entamoeba histolytica.

\section{Introduction}

Human amoebiasis due to Entamoeba histolytica is mainly associated with morbidity thus affecting the quality of life and pace of developmental activities of countries with warm climatic conditions. A consistently high global incidence of this disease has been reported from surveys carried out at different intervals of time (Beltran, 1948; Stanley, 2003). This disease also poses a challenge to our national health program. A number of therapeutic agents possessing potent in vitro action against trophozoites of $E$. histolytica have been used to combat this disease. So far, these have been found to be either toxic or providing only symptomatic relief that leads scientists to obtain novel molecules with antiamoebic activity from natural products, either terrestrial plants or marine organisms. The scope of natural products have widened with the inclusion of marine biota.

Drug from marine resources is an area which offers an unprecedented opportunity for their pharmacological exploration and hence has received great attention during recent years for natural product chemistry. Secondary metabolites produced in marine organisms could be the source of bioactive substances and useful in modeling compounds for drugs (Faulkner, 2001; Haefner, 2003; Anjaneyulu et al., 2001; Anjaneyulu et al., 2000; Nguyen et al., 2013). Marine microorganisms, whose immense genetic and biochemical diversity is only beginning, likely to become a rich source of novel chemical entities for the discovery of more effective drugs. In our ongoing program to search for natural products with unique structural features and pronounced biological activities, a marine organism, A. lecanora (Jaeger) was collected from south Andaman coast of India for study of chemical composition and antiamoebic activity. We, here in, report the results of our preliminary antiamoebic screening.

\section{Material and Methods}

Collection of the sample: The Actinopyga lecanora (Jaeger), a soft coral sea cucumber was collected from South Andaman coast of India. A voucher specimen (number 388) of this collection has been preserved in the Herbarium of the Botany Division, Central Drug Research Institute, Lucknow, India.

Extraction: Freshly collected sea cucumber $(1.0 \mathrm{~kg})$ was cut into small pieces and extracted with methanol $(4 \times 4$ lit $)$ at room temperature. The combined extract was

Correspondence to: Dr. Vijai Lakshmi; Tel: +91- (0522)2254604; E-mail: vijlakshmius@yahoo.com 
filtered, concentrated under reduced pressure below $45^{\circ} \mathrm{C}$ in a rotavapour to yield a viscous mass $(20.0 \mathrm{~g})$. Use for antiamoebic activity.

Test models and methodology for antiamoebic activity: Axenic culture of E. histoyitica (200: NIH) maintained in TYI-S-33 medium (Diamond et al., 1978) has been used for in vitro screening. Xenic culture 2771 isolated from an acute case and maintained in Robinson's medium (Robinson, 1968) was used to produce experimental caecal amoebiasis in rats.

Evaluation of in-vitro amoebicidal activity: The stock solution of the test agent was prepared by adding small quantity of DMSO and required amount of water. Further serial dilutions were prepared using triple glass distilled water. Amoebic inoculum $(0.1 \mathrm{ml})$ containing approximately 2000 trophozoites were added to the cavities of shallow cavity slides to which the test sample $(0.1 \mathrm{ml})$ in its required dilution was added. Each cavity was then sealed with cover slip. The slides were kept in the moist chamber at $37^{\circ} \mathrm{C}$. Observations were taken at 24 and $48 \mathrm{hrs}$ intervals. The activity of the test agent at the particular dilution was related with cent percent mortality. Metronidazole was used as the standard drug. Duplicate sets were kept for each dilution (Das, 1975).

\section{Antiamoebic activity by in vivo test model}

Experimental production of caecal amoebiasis in rats: Rats were fed on autoclaved rice diet for seven days prior to infection. The caecal contents of these rats attain a $\mathrm{pH}$ of 5.5 to 7.0 without the occurrence of free ammonia which is toxic to these amoebae (Prasad and Bansal, 1983; Leitch, 1988) thus aiding in the consistent production of caecal infection. Rats under ether anaesthesia were inoculated intracaecally with 0.2 to $0.3 \mathrm{ml}$ of amoebic inoculum containing $10 \times 10^{4}$ trophozoites of $E$. histolytica and the abdominal lesion sutured. After 48 hours, the infected rats were ready for therapeutic evaluation of test agents as trophozoites of E. histolytica. These were visible microscopically in the contents and scrapings of the caecal wall. The animals were divided into two groups. One group was given oral administration of the drug, while the other group served as control group.

Treatment schedule: The test material was suspended in distilled water using gum acacia. The rats were orally administered with the test agent at $900 \mathrm{mg} / \mathrm{kg}$ b.w. with the help of a feeding needle once daily for five consecutive days. The rats were sacrificed 48 hours after the last dose of test material with an overdose of ether anesthesia and the caecum was examined for trophozoites of E. histolytica. The reported method of Neal (1951) was used to evaluate the degree of infection.

\section{Results and Discussion}

The effects of the A. lecanora extract on trophozoites of $E$. histolytica in vitro and against caecal amoebiasis of rats are described in Table 1. The in vivo therapeutic efficacy of the crude extract showed that the methanol extract when administered at a dose of $900 \mathrm{mg} / \mathrm{kg}$ body weight for five days resulted $88 \%$ cures. It is not uncommon that marine organisms possess activity against pathogenic bacteria, fungus and protozoa. Bhosale (1999) has reported that terpenoids isolated from Pseudoplenauria wagenaari possess antiamoebic activity in vitro. Lobane diterpene derivatives of this organism were active against phytopathogenic fungus, Cladosporium cucumerinum, gram positive bacteria, Bacillus subtilis, and yeast, Saccharomyces cerevisiae (Edrada et al., 1998). Similar derivatives have also been isolated from other marine organisms (Shin and Fenical, 1991). In view of the results presented it is evident that marine organisms can provide lead compounds for treating amoebiasis. Thus, the ocean with its innumerable biota offers a challenge to both chemists and biologists alike as it is a large reservoir of novel chemical entities with therapeutic potential for human use.

The results assumed to be significant when viewed regarding the condition of the caecal wall. The caecum of rats receiving the crude extract appeared normal with thin caecal wall comparable to the rats treated with the standard drug metronidazole $(100 \mathrm{mg} / \mathrm{kg}$ body weight). However, the caecal contents of the rats treated with the test agents although being normal was slightly less formed as compared to the metronidazole treated rats. The result seems to be more interesting when the caecum of the treated rats was compared with the untreated rat caecum, which was shapeless with ulcers on the walls and with mucous and very little faecal matter contents. It is apparent from the results that A. lecanora possesses significant amoebicidal activity against $E$. histolytica. This 
validates the promise held by the ocean as a source of therapeutic agents against human ailments.

Table 1. Results of antiamoebic activity of A. lecanora against E. histolytica in in-vitro and in vivo models.

\begin{tabular}{|l|c|c|c|}
\hline \multirow{2}{*}{ Test agent } & \multicolumn{3}{|c|}{ Antiamoebic activity against E. histolytica } \\
\cline { 2 - 4 } & \begin{tabular}{c} 
In- vitro \\
MIC \\
\cline { 2 - 4 }
\end{tabular} & \multicolumn{2}{|c|}{ In-vivo } \\
\cline { 2 - 4 } & Dose (mg/kg b.w.) & $\begin{array}{c}\% \\
\text { inhibitio } \\
\mathrm{n}\end{array}$ \\
\hline $\begin{array}{l}\text { Methanol } \\
\text { extract }\end{array}$ & 125 & $900(5)$ & 88 \\
\hline $\begin{array}{l}\text { Metronida } \\
\text { zole } \\
\text { (Standard) }\end{array}$ & 8 & $500(5)$ & 60 \\
\hline
\end{tabular}

\section{Acknowledgements}

We are grateful to the Director CSIR-CDRI for providing excellent research facilities at Central Drug Research Institute, Lucknow. Ministry of Earth Sciences, Government of India, New Delhi is acknowledged for financial support. One of the authors (VL) is thankful to the Head-HRDG-CSIR for financial support in the form of Emeritus Scientistship, which enabled to compile the research work. The authors also wish to thank to Dr. M. N. Srivastava, Scientist, Central Drug Research Institute, Lucknow, India for collection of the marine samples.

\section{References}

Anjaneyulu, V., Rao, P.V.S., Radhika. P., Laatsch. H. and Mishra., R.N. 2000. A new lipid glycoside from two Sinularia species of Andaman and Nicobar Islands, Inian J. Chem. 39,121-124

Anjaneyulu, V., Rao, P.V.S., Radhika, P., Laatsch, H. and Asolkar, R.N. 2001. A new glycolipid and a new monohydroxy sterol from Cladiella species of Andaman and Nicobar Islands. Indian J. Chem. 40,405-409

Beltran, F. 1948. Epidemiologica de las infeciones on Entamoeba histolytica. Sect. VIII, Protozoan diseases. Proceedings of the $4^{\text {th }}$ International Congress on Tropical Medicine and Malaria, Washington, 2, p. 1056.
Bhosale, S.H., Jagtap,T.G. and Naik, C.G. 1991. Antifungal activity of some marine organisms from India against food spaelage Aspergillus strains, Mycopathologia, 147, 133138.

Das, S.R. 1975. A novel and rapid method for in vitro testing of antiamoebic agents against aerobic and anaerobic amoebae growing axenically or with bacteria. Curr. Sci. 44, 463.

Diamond, L.S., Harlow, D.R. and Cunnick, C.C. 1978. A new mediun for the axenic cultivation of E. histolytica and other Entamoeba. Trans. Roy. Soc. Trop. Med. Hyg. 72, 431.

Edrada, R.A., Proksh, P., Wray, V., Wilte, L. and Ofrogen, L.V. 1998. Four new bioactive lobane diterpenes of the soft coral Lobophytum pauciflorum from Mindoro, Phillipines. J. Nat. Prod. 61,358.

Faulkner, D.J. 2001. Marine natural products. Nat. Prod. Rep. $18,1$.

Haefner, B. 2003. Drugs from the deep marine natural products as drug candidates. Drug Discovery Today 8, 536.

Leitch, G.J. 1988. Intestinal luminal and mucosal microclimate $\mathrm{H}^{-}$and $\mathrm{NH}^{+}$concentration as factors in the etiology of experimental amoebiasis. Am. J. Trop. Med. Hyg. 38,480.

Neal, R.A. 1951. Some observations in the variations of virulence and response to chemotherapy of strains of Entamoeba histolytica. Trans. Roy. Soc. Trop. Med. Hyg. 44, 439-452.

Nguyen, P.T., Nguyen, H.N., Nguyen, X.C., Bui, H.T., TranHQ, Nguyen, T.T.N., Bui, T.T.L., Seo, Y.Y., Chun, H.C., Sohyun, K., Doobyeong, C., Young-Sang, K., Phan, V.K., Chau, V.M. and Young, H.K. 2013. Steroidal constituents from the soft coral Sinularia dissecta and their Inhibitory effects on Lipopolysac- charide-Stimulated production of pro-inflammatory cytokines in Bone Marrow- Derived dendritic Cells, Bull. Korean Chem. Soc. 34, 3949.

Prasad, B.N.K. and Bansal, I. 1983. Interrelationship between faecal $\mathrm{pH}$ and susceptibility to Entamoeba histolytica infection of rats. Trans. Royal Soc. Trop. Med. Hyg. 77, 271.

Robinson, G.R. 1968. Laboratory cultivation of some human parasitic amoeba. J. Gen. Microbiol. 53, 19.

Shin, J. and Fenical, W. 1991. Fucoside A-D anti-inflammatory diterpenoid glycoside of new structural classes from the Caribbean gorgonian Eunacea fusca. J. Org. Chem. 56, 3153.

Stanley, S.L. Jr. Amoebiasis, 2003. The Lancet. 361, 1025-1034. 